\title{
Impact of Age on Risk Factors and Clinical Manifestations of Acute Coronary Syndrome: Observations From the Coronary Care Unit of Sulaimani, Iraq
}

\author{
Amanj Abubakr Jalal Khaznadar ${ }^{1 *}$, Rebin Wahid Salh ${ }^{2}$ \\ ${ }^{1}$ Department of Medicine, College of Medicine, University of Sulaimani, Sulaimani, Iraq \\ ${ }^{2}$ General Teaching Hospital, Sulaimani, Iraq
}

*Corresponding Author: Amanj Abubakr Jalal Khaznadar, Assistant Professor, DIM, FICMS, FRCP (London), Department of Medicine, College of Medicine, University of Sulaimani, Sulaimani, Iraq. Tel: +964-7701577711, Email: amanjxaznadar@yahoo.com

Received August 22, 2019; Accepted February 24, 2020; Online Published March 18, 2020

\begin{abstract}
Background: ST-segment elevation myocardial infarction (STEMI) and non-ST-segment elevation myocardial infarction (NSTEMI ) are common types of acute coronary syndrome which are associated with the risk factors of age, obesity, hypertension, and diabetes. Objective: The present study aimed to examine the effects of age on the risk factors and clinical symptoms of acute coronary syndrome.

Methods: A cross-section prospective study was conducted on 125 patients with acute coronary syndrome chosen by non-probability convenience sampling method in the coronary care unit in Sulaimani, the Kurdistan region of Iraq. Acute coronary syndrome types were diagnosed through clinical presentations, electrocardiography (ECG), and troponin test. Data was collected using a researcherbased checklist through face-to-face interviews.

Results: The results indicated that males were the dominant group. The age group 45-65 had the highest prevalence rate of acute coronary syndrome. The most frequent risk factors for acute coronary syndrome were hypertension (54.4\%), dyslipidemia (52\%), smoking $(42.4 \%)$, and diabetes mellitus (38.4\%). Typical chest pain was found to be the most frequent clinical presentation $(88 \%)$. There was a significant difference between the age groups in terms of the effect of age on typical and atypical symptoms; however, neither age nor typical/atypical symptoms had a significant effect on type of acute coronary syndrome. Similarly, family history, hypertension, diabetes mellitus, obesity, smoking, physical inactivity, and dyslipidemia had no effect on type of acute coronary syndrome.

Conclusion: Age is a predictive factor for acute coronary syndrome, but family history, hypertension, diabetes mellitus, obesity, smoking, physical inactivity, and dyslipidemia cannot predict acute coronary syndrome.

Keywords: Acute Coronary Syndrome, Myocardial Infarction, ST-segment Elevation Myocardial Infarction (STEMI), Non-ST-segment Elevation Myocardial Infarction (NSTEMI), Iraq
\end{abstract}

\section{Background}

Cardiovascular diseases (CVDs) have been regarded as main causes of mortality in both developing and developed countries. ${ }^{1,2}$ The prevalence of CVDs has been reported to be increasing at a remarkable pace in both low- and middleincome countries. ${ }^{3}$ CVD can lead to the development of coronary artery disease in which blood flow to the heart is limited, which, in turn, gives way to the development of acute myocardial infarction (AMI), one of the 5 leading causes of mortality. ${ }^{4}$

Acute coronary syndrome (ACS) includes a number of coronary artery diseases, such as ST-segment elevation myocardial infarction (STEMI), non-ST-segment elevation myocardial infarction (NSTEMI), and unstable angina
(UA). ${ }^{5}$ Myocardial infarction is a clinical condition in which blood flow to the myocardium is disturbed, leading to inadequate oxygenation which, in turn, results in myocardial injury and subsequent infarction. ${ }^{6}$ According to research conducted in Iraq, AMI leads to death in $16.1 \%$ of AMI patients, ${ }^{7}$ a rate higher than that seen in other developing countries, such as Iran (9.4\%) and Saudi Arabia $(3.0 \%) .8$

Research has indicated that there are some nonmodifiable risk factors for CVD, and thus for ACS, including male gender, a family history of CVD, age over 55 years, and genetics as well as some modifiable risk factors such as unhealthy diet, diabetes mellitus (DM), obesity, physical inactivity, systemic arterial hypertension, smoking, and

Copyright $\odot 2020$ The Author(s). This is an open-access article distributed under the terms of the Creative Commons Attribution License (http:// creativecommons.org/licenses/by/4.0), which permits unrestricted use, distribution, and reproduction in any medium, provided the original work is properly cited. 
dyslipidemia. ${ }^{10-12}$ Among the abovementioned risk factors, old age has been regarded as a potent predictor of mortality in patients with AMI. ${ }^{13-15}$ ACS is associated with typical and atypical symptoms. Typical symptoms of ACS include jaw/neck pain, sweating, shortness of breath, arm pain, and chest pain; its atypical symptoms are mid-back pain, vomiting, palpitation, weakness, and fainting. ${ }^{16,17}$

Quite a large number of research studies have focused on the correlation between ACS and risk factors like smoking, dyslipidemia, and hypertension ${ }^{18-20}$; however, the relationship between age and atypical and typical symptoms of ACS has hardly been studied. ${ }^{21,22}$

\section{Objective}

To fill this research gap, the present study aimed to investigate the influence of age on the presentation of ACS and to examine whether the risk factors of ACS change according to age.

\section{Methods}

\subsection{Study Design and Subjects}

This cross-sectional prospective study was carried out over a period of 8 months from August 2018 to March 2019 and included 125 patients diagnosed with AMI (both STEMI and NSTEMI). Non-probability convenience sampling was used to select participants from among all AMI patients admitted to the coronary care unit in Sulaimani, the Kurdistan region of Iraq. AMI was diagnosed using clinical presentations, electrocardiography (ECG), and troponin test.

\subsection{Inclusion/Exclusion Criteria}

The study inclusion criteria were AMI and having undergone treatment; exclusion criteria comprised having a history of pulmonary embolism, pneumonia, congestive occlusive pulmonary disease, heart failure, or cerebrovascular accident. Patients were assigned into three groups according to their age: young group ( $<45$ years), middle-age group (45-65 years), and old group ( $>65)$ based on similar studies on the same subject. ${ }^{23-25}$

\subsection{Data Collection}

The required data was collected by a researcher-designed checklist aimed at gathering data on patients' typical and atypical symptoms of ACS at the time of their admission to the Coronary Care Unit. To classify typical and atypical symptoms, the Milner proposed classification was utilized. ${ }^{26}$ Data collection was carried out by the researcher and two other nurses who were trained before the study using face-to-face interviews with the participants. Other required data, including demographics like age and gender and risk factors such as obesity (BMI $\geq 30$ ), smoking, diabetes, hypertension, and so on, was collected from patients' current records.

\subsection{Statistical Analysis}

The collected data was analyzed using Statistics for Windows (version 20.0. Armonk, NY: IBM Corp.). Categorical data was analyzed through descriptive statistics, and the results were expressed as numbers (frequency) and percentages. The chi-square test was used to determine correlations between categorical variables; a $P$ value less than or equal to 0.05 was considered significant. Fisher exact test was used instead of the chi-square test when the expected cell count of more than $20 \%$ equaled less than five.

\section{Results}

In a prospective study, 125 patients diagnosed with AMI were recruited in order to examine the effect of age on ACS presentation and to determine whether it leads to changes in ACS risk factors. The demographic characteristics of patients in the present study revealed that nearly half (41.6\%) belonged to the age group 45-65 years, 36.8\% were over 65 years of age, and $21.6 \%$ were under 45 years of age. Most of the patients (67.2\%) were male, and $32.8 \%$ were female (Table 1).

The results demonstrated that the most frequent risk factors for AMI were hypertension (seen in 68 [54.4\%] patients), dyslipidemia (seen in 65 [52\%] patients, smoking (seen in 53 [42.4\%] patients), and DM (seen in 48 [38.4\%] patients. Other risk factors were obesity, family history, and physical inactivity in 30 (24\%), 18 (14.4\%), and 4 (3.2\%) patients, respectively (Table 2).

The results of the present study also showed that all patients with AMI had either typical or atypical chest pain ( $88 \%$ and $12 \%$, respectively (Table 3 ).

As revealed by the results, a near equal number of patients had STEMI as had non-STEMI types of AMI, such that $50.4 \%$ and $49.6 \%$ of them had STEMI and non-STEMI types, respectively (Table 4 ).

\begin{tabular}{lll}
\multicolumn{2}{l}{ Table 1. Demographic Characteristics of Patients } \\
\hline Characteristics & No. & $\%$ \\
\hline Age $(y)$ & 27 & 21.6 \\
$<45$, young & 52 & 41.6 \\
$45-65$, middle age & 46 & 36.8 \\
$>65$, old age & 125 & 100.0 \\
Total & & \\
Gender & 41 & 32.8 \\
Female & 84 & 67.2 \\
Male & 125 & 100.0 \\
Total &
\end{tabular}

Table 2. Frequency of Risk Factors in Patients

\begin{tabular}{lll}
\hline Risk factors & $\begin{array}{l}\text { Positive } \\
\text { No. }(\%)\end{array}$ & $\begin{array}{l}\text { Negative } \\
\text { No. }(\%)\end{array}$ \\
\hline Family history & $18(14.4)$ & $107(85.6)$ \\
Hypertension & $68(54.4)$ & $57(45.6)$ \\
Diabetes mellitus & $48(38.4)$ & $77(61.6)$ \\
Obesity & $30(24)$ & $95(76)$ \\
Smoking & $53(42.4)$ & $72(57.6)$ \\
Physical inactivity & $4(3.2)$ & $121(96.8)$ \\
Dyslipidemia & $65(52)$ & $60(48)$ \\
\hline
\end{tabular}


Table 3. Types of Chest Pain in Patients

\begin{tabular}{llll}
\hline Symptoms & & No. & $\%$ \\
\hline \multirow{2}{*}{ Chest pain } & Typical & 110 & $88 \%$ \\
& Atypical & 15 & $12 \%$ \\
Total & & 125 & $100 \%$ \\
\hline
\end{tabular}

Table 4. Types of Myocardial Infarction in Patients

\begin{tabular}{lcc}
\hline ACS & No. & $\%$ \\
\hline STEMI & 63 & 50.4 \\
NSTEMI & 62 & 49.6 \\
Total & 125 & 100
\end{tabular}

Abbreviations: ACS, acute coronary syndrome; STEMI, ST-elevation myocardial infarction; NSTEMI, non-ST-segment elevation myocardial infarction.

The results revealed that the distribution of typical and atypical symptoms of AMI were significantly different between age groups $(P=0.03)$ (Table 5$)$. Therefore, age can be considered as a predictive factor for types of ACS symptoms.

However, the results showed that the three age groups were not significantly different in terms of type of ACS $(P=0.06)$; therefore, patient age cannot be considered a predictive factor for type of ACS or myocardial infarction (MI) (Table 6).

The current results revealed that age and typical/atypical symptoms did not have a significant effect on ACS in any of the age groups (Table 7).

Finally, the results of the present study demonstrated that none of the studied risk factors (i.e. family history, hypertension, diabetes mellitus, obesity, smoking, physical inactivity, and dyslipidemia) had a significant effect on ACS in any of the age groups $(P>0.05)$ (Table 8$)$.

Table 5. Distribution of Symptoms According to Age

\begin{tabular}{lcccc}
\hline \multirow{2}{*}{ Age Group } & \multicolumn{2}{c}{ Symptoms } & \multirow{2}{*}{ Total } & \multirow{2}{*}{$\boldsymbol{P}$ Value } \\
\cline { 2 - 3 } & $\begin{array}{c}\text { Typical } \\
\text { No. }(\%)\end{array}$ & $\begin{array}{c}\text { Atypical } \\
\text { No. }(\%)\end{array}$ & No. $(\%)$ & \\
\hline$<45$ young & $25(92.6)$ & $2(7.4)$ & $27(100.0)$ & \\
\hline $45-65$ middle age & $49(94.2)$ & $3(5.8)$ & $52(100.0)$ & 0.03 \\
$>$ 65 old age & $36(78.3)$ & $10(21.7)$ & $46(100.0)$ & \\
\hline Total & $110(88.0)$ & $15(12.0)$ & $125(100.0)$ & \\
\hline
\end{tabular}

Table 6. Distribution of ASC in Different Age Groups

\begin{tabular}{lcccc}
\hline \multirow{2}{*}{ Age Group } & \multicolumn{2}{c}{ Symptoms } & \multirow{2}{*}{$\begin{array}{c}\text { Total } \\
\text { No. }(\%)\end{array}$} & \multirow{2}{*}{$\boldsymbol{P}$ Value } \\
\cline { 2 - 3 } & $\begin{array}{c}\text { STEMI } \\
\text { No. }(\%)\end{array}$ & $\begin{array}{c}\text { NSTEMI } \\
\text { No. }(\%)\end{array}$ & No. & \\
\hline$<45$ young & $12(63.0)$ & $10(37.0)$ & $27(100.0)$ & \\
\hline $45-65$ middle age & $29(55.8)$ & $23(44.2)$ & $52(100.0)$ & \multirow{2}{*}{0.06} \\
$>$ 65 old age & $17(37.0)$ & $29(63.0)$ & $46(100.0)$ & \\
\hline Total & $63(50.4)$ & $62(49.6)$ & $125(100.0)$ & \\
\hline
\end{tabular}

Abbreviations: ACS, acute coronary syndrome; STEMI, ST-elevation myocardial infarction; NSTEMI, non-ST-segment elevation myocardial infarction.

\section{Discussion}

Of the recruited 125 patients with AMI, most of them (41.6\%) were between the ages of 45 and 65 years, followed by 46 patients (36.8\%) over the age of 65 and $27(21.6 \%)$ under the age of 45 . These results clearly indicate that AMI is more prevalent among the middle-aged group (45-65 years old). Similar findings have been reported in previously conducted studies. ${ }^{23,24,27}$ The results also revealed that AMI was more prevalent among male patients with $67.2 \%$, while a smaller percentage of females (32.8\%) had AMI. This finding is in good agreement with previous studies that have referred to male gender as a risk factor for ACS. ${ }^{26,28-30}$

Hypertension was found to be the most frequent risk factor among the studied AMI patients, such that 65 cases (54.4\%) had hypertension. Other most frequent risk factors were observed to be dyslipidemia (52\%), smoking (42.4\%), diabetes mellitus (38.4\%), obesity (24\%), family history (14.4\%), and physical inactivity (3.2\%). Similar to the present study, Mirza et al conducted a study in Sulaimani, Iraq to examine risk factors for ACS among patients under the age of 40 years. They concluded that obesity, smoking, number of diseased vessels, hypertension, family history of ACS, and diabetes mellitus were, sequentially, the most frequent risk factors for ACS. ${ }^{30}$ This finding is also in line with many other previously conducted studies that have referred to smoking, hypertension, diabetes, obesity, and dyslipidemia as risk factors for the development of ACS. ${ }^{31-34}$

Chest pain has been introduced as the most common presentation of an ACS. Reports indicate that $20 \%$ to $25 \%$ of patients who refer to the emergency department are later found to have ACS. ${ }^{34}$ Similarly, the results of the present study demonstrated that most of the patients with AMI (88\%) had typical chest pain and the rest $12 \%$ had atypical chest pain. This finding is also in line with those of the study conducted by El-Menyar et al. ${ }^{35}$

The current results further indicated that the number of patients with STEMI was almost equal that of patients with NSTEMI types of AMI. However, based on a report by the American Heart Disease Association Statistics Committee and Stroke Statistics Subcommittee, two-thirds of patients have NSTEMI and the rest have STEMI. ${ }^{36}$ Conversely, in their study carried out on 2090 patients with ACS, Montalescot et al reported that a larger number of patients had STEMI. ${ }^{37}$ These differences can only be because of the sampling methods and procedures.

The results of the present study indicated that the three studied age groups were significantly different in terms of distribution of typical and atypical symptoms. Typical symptoms were more prevalent in the patients under the age of 65 (i.e. those in the $<45$ and $45-56$ age groups), while the old age group (over 65) had more atypical presentations. This finding is in good agreement with those of the study carried out by El-Menyar et al, who observed that older patients with ACS usually develop atypical symptoms. ${ }^{35}$

The present study revealed that the three age groups were different regarding the distribution of types of ACS 
Table 7. Collective Effects of Age and Symptoms on ACS

\begin{tabular}{|c|c|c|c|c|c|}
\hline \multirow[b]{2}{*}{ Age } & \multirow[b]{2}{*}{ Symptoms } & \multicolumn{2}{|c|}{ ACS } & \multirow[b]{2}{*}{$\begin{array}{c}\text { Total } \\
\text { No. }(\%)\end{array}$} & \multirow[b]{2}{*}{$P$ value } \\
\hline & & $\begin{array}{c}\text { STEMI } \\
\text { No. }(\%)\end{array}$ & $\begin{array}{l}\text { NSTEMI } \\
\text { No. }(\%)\end{array}$ & & \\
\hline \multirow{3}{*}{$\begin{array}{l}<45 \\
\text { Young }\end{array}$} & Typical & $15(60.0)$ & $10(40.0)$ & 25 (100.0) & \multirow{3}{*}{0.260} \\
\hline & Atypical & $2(100.0)$ & $0(0.0)$ & $2(100.0)$ & \\
\hline & Total & $17(63.0)$ & $10(37.0)$ & $27(100.0)$ & \\
\hline \multirow{3}{*}{$\begin{array}{l}45-65 \\
\text { Middle age }\end{array}$} & Typical & $27(55.1)$ & $22(44.9)$ & 49 (100.0) & \multirow{3}{*}{0.695} \\
\hline & Atypical & $2(66.7)$ & $1(33.3)$ & $3(100.0)$ & \\
\hline & Total & $29(55.8)$ & $23(44.2)$ & $52(100.0)$ & \\
\hline \multirow{3}{*}{$\begin{array}{l}>65 \\
\text { Old age }\end{array}$} & Typical & $15(41.7)$ & $21(58.3)$ & $36(100.0)$ & \multirow{3}{*}{0.209} \\
\hline & Atypical & $2(20.0)$ & $8(80.0)$ & $10(100.0)$ & \\
\hline & Total & $17(37.0)$ & $29(63.0)$ & 46 (100.0) & \\
\hline \multirow{3}{*}{ Total } & Typical & $57(51.8)$ & $53(48.2)$ & $110(100.0)$ & \multirow{3}{*}{0.390} \\
\hline & Atypical & $6(40.0)$ & $9(60.0)$ & 15 (100.0) & \\
\hline & Total & $63(50.4)$ & 62 (49.6) & 125 (100.0) & \\
\hline
\end{tabular}

Abbreviations: ACS, acute coronary syndrome; STEMI, ST-elevation myocardial infarction; NSTEMI, non-ST-segment elevation myocardial infarction.

Table 8. Effects of Age and the Risk Factors on ACS

\begin{tabular}{|c|c|c|c|c|c|}
\hline \multirow[b]{2}{*}{ Risk Factors } & \multirow[b]{2}{*}{ Age Groups } & \multicolumn{2}{|c|}{ ACS } & \multirow[b]{2}{*}{$\begin{array}{c}\text { Total } \\
\text { No. }(\%)\end{array}$} & \multirow[b]{2}{*}{$P$ value } \\
\hline & & $\begin{array}{c}\text { STEMI } \\
\text { No. }(\%) \\
\end{array}$ & $\begin{array}{l}\text { NSTEMI } \\
\text { No. }(\%) \\
\end{array}$ & & \\
\hline \multirow{4}{*}{ Family history } & $<45$ Young & $5(55.6)$ & $4(44.4)$ & $9(100.0)$ & 0.512 \\
\hline & 45-65 Middle age & 3 (42.9) & $4957.1)$ & $7(100.0)$ & 0.423 \\
\hline & $>65$ Old age & $1(50.0)$ & $1(50.0)$ & $2(100.0)$ & 0.610 \\
\hline & Total & $9(50.0)$ & $9(50.0)$ & $18(100.0)$ & 0.912 \\
\hline \multirow{4}{*}{ Hypertension } & $<45$ Young & $3(100.0)$ & $0(0.0)$ & $3(100.0)$ & 0.159 \\
\hline & 45-65 Middle age & $13(46.4)$ & $15(53.6)$ & $28(100.0)$ & 0.143 \\
\hline & $>65$ Old age & $14(37.8)$ & $23(62.2)$ & $37(100.0)$ & 0.802 \\
\hline & Total & $30(44.1)$ & $38(55.9)$ & 68 (100.0) & 0.125 \\
\hline \multirow{4}{*}{ Diabetes mellitus } & $<45$ Young & $5(62.5)$ & $3(37.5)$ & $8(100.0)$ & 0.974 \\
\hline & 45-65 Middle age & $8(47.1)$ & 9 (52.9) & $17(100.0)$ & 0.378 \\
\hline & $>65$ Old age & $8(34.8)$ & $15(65.2)$ & $23(100.0)$ & 0.760 \\
\hline & Total & $21(43.8)$ & $27(56.3)$ & $48(100.0)$ & 0.240 \\
\hline \multirow{4}{*}{ Obesity } & $<45$ Young & $3(60.0)$ & $2(40.0)$ & $5(100.0)$ & 0.879 \\
\hline & 45-65 Middle age & $5(41.7)$ & $7(58.3)$ & $12(100.0)$ & 0.262 \\
\hline & $>65$ Old age & $6(46.2)$ & $7(53.8)$ & $13(100.0)$ & 0.417 \\
\hline & Total & $14(46.7)$ & $16(53.3)$ & $30(100.0)$ & 0.639 \\
\hline \multirow{4}{*}{ Smoking } & $<45$ Young & $11(73.3)$ & $4(26.7)$ & $15(100.0)$ & 0.212 \\
\hline & 45-65 Middle age & $14(56.0)$ & $11(44.0)$ & 25 (100.0) & 0.974 \\
\hline & $>65$ Old age & $7(53.8)$ & $6(46.2)$ & $13(100.0)$ & 0.136 \\
\hline & Total & $32(60.4)$ & $21(39.6)$ & $53(100.0)$ & 0.056 \\
\hline \multirow{4}{*}{ Physical inactivity } & $<45$ Young & $1(100.0)$ & $0(0.0)$ & $1(100.0)$ & 1.00 \\
\hline & 45-65 Middle age & $1(100.0)$ & $0(0.0)$ & $1(100.0)$ & 0.369 \\
\hline & $>65$ Old age & $1(33.3)$ & $2(66.7)$ & $3(100.0)$ & 0.893 \\
\hline & Total & $2(50.0)$ & $2(50.0)$ & $4(100.0)$ & 0.987 \\
\hline \multirow{4}{*}{ Dyslipidemia } & $<45$ Young & $8(57.1)$ & $6(42.9)$ & $14(100.0)$ & 0.516 \\
\hline & 45 -65 Middle age & $16(61.5)$ & $10(38.5)$ & $26(100.0)$ & 0.402 \\
\hline & $>65$ Old age & $10(40.0)$ & $15(60.0)$ & 25 (100.0) & 0.641 \\
\hline & Total & $34(52.3)$ & $31(47.7)$ & 65 (100.0) & 0.657 \\
\hline
\end{tabular}


(STEMI and NSTEMI); however, this difference was not significant. This finding is not in line with the results obtained by Asgar Pour et al, who stated that older patients with an average age of 71.32 years and younger patients with a mean age of 53.75 years were significantly different in terms of ACS type. ${ }^{17}$ This difference can be attributed to differences in classification of the age groups between that study and the present one. Moreover, Asgar Pour et al considered UA in addition to STEMI and NSTEMI, which can have a significant effect on the discrepancy between the results of the 2 studies. Reda et al also concluded that there was a significant difference between age groups regarding ACS types ${ }^{38}$; however, similar to Asgar Pour et al, they studied three types of ACS (STEMI, NSTEMI, and UA), which can explain the observed difference between those studies and the present one.

The results of the present study demonstrated that the variables of age and typical/atypical symptoms of ACS had no significant effect on type of ACS (STEMI or NSTEMI) in any of the studied age groups. No previously conducted study was found to have compared the effect of typical/ atypical symptoms on STEMI and NSTEMI in the same age groups; therefore, this finding cannot be compared to any other findings.

Based on the current results, it was concluded that none of the risk factors (family history, hypertension, diabetes mellitus, obesity, smoking, physical inactivity, and dyslipidemia) had a significant effect on the development of ACS in the studied age groups. However, in the present study, intergroup comparisons were not performed. Asgar Pour et al compared an older group with ACS with a younger one and concluded that the two groups were significantly different regarding smoking, obesity, and hypertension. ${ }^{17}$ Similar to the current results, however, Reda et al concluded that obesity and hypertension did not have a significant effect on the development of ACS. The differences between the studies can be attributed to differences in age grouping, number of patients, and other uncontrollable variables.

The present study had some limitations, the first of which was the limited number of patients, which can restrict the generalizability of the results to other populations. Another limitation was that different age groups were not compared (intergroup comparison) regarding the effect of the studied risk factors on the development of their ACS. Therefore, future studies are recommended to recruit a larger study sample and to compare different age groups regarding the risk factors proposed by the relevant literature.

\section{Conclusion}

Hypertension, smoking, and diabetes are the most frequent risk factors for ACS. Typical chest pain is the most common clinical presentation of ACS; however, atypical chest pain is frequent among older patients. Different age groups differ significantly in typical and atypical symptoms of ACS. However, age cannot be considered as a predictive factor for the type of ACS (i.e. STEMI or

\section{Research Highlights}

What Is Already Known?

Research has indicated that there are some nonmodifiable risk factors for CVD, and thus for ACS, including male gender, a family history of CVD, age over 55 years, and genetics as well as some modifiable risk factors, such as unhealthy diet, DM, obesity, physical inactivity, systemic arterial hypertension, smoking, and dyslipidemia. Among the abovementioned risk factors, old age has been regarded as a potent predictor of mortality in patients with AMI. ACS is associated with typical and atypical symptoms. Typical symptoms of ACS include jaw/neck pain, sweating, shortness of breath, arm pain, and chest pain, and its atypical symptoms are midback pain, vomiting, palpitation, weakness, and fainting..

\section{What This Study Adds?}

Quite a large number of research studies have focused on the correlation between ACS and risk factors like smoking, dyslipidemia, and hypertension; however, the relationship between age and atypical/ typical symptoms of ACS has hardly been studied. To fill this research gap, the present study investigated the influence of age on the presentation of ACS and examined whether the risk factors of ACS change according to age.

NSTEMI). Also, STEMI and NSTEMI cannot be predicted through typical and atypical symptoms. Finally, family history, hypertension, diabetes mellitus, obesity, smoking, physical inactivity, and dyslipidemia have no significant effect on the development of ACS. Following the findings of the present study, it is recommended that patients with risk factors like hypertension, smoking, and diabetes be provided with a diagnostic examination to determine the presence or absence of ACS. Moreover, age can be used as a factor to predict the type of ACS presentations.

\section{Authors' Contributions}

RWS: Study conception and design, acquisition of data, data analysis and interpretation, manuscript writing and critical revisions. AAJK: acquisition of data and critical revisions of the manuscript for intellectual content. All authors read and approved the final manuscript.

\section{Conflict of Interest Disclosures}

The authors declare that they have no conflicts of interest.

\section{Ethical Approval}

In order to take ethical considerations into account, the necessary approval was obtained from the Ethics and Scientific Committee of the College of Medicine, University of Sulaimani. Moreover, written informed consent was obtained from all patients after they were provided with the necessary explanation about the aims, methods, and duration of the study. 


\section{References}

1. Pagidipati NJ, Gaziano TA. Estimating deaths from cardiovascular disease: a review of global methodologies of mortality measurement. Circulation. 2013;127(6):749-756. doi:10.1161/circulationaha.112.128413.

2. Rogers HW, Weinstock MA, Feldman SR, Coldiron BM. Incidence estimate of nonmelanoma skin cancer (keratinocyte carcinomas) in the US population, 2012. JAMA Dermatol. 2015;151(10):1081-1086. doi:10.1001/ jamadermatol.2015.1187.

3. Nag T, Ghosh A. Cardiovascular disease risk factors in Asian Indian population: a systematic review. J Cardiovasc Dis Res. 2013;4(4):222-228. doi:10.1016/j.jcdr.2014.01.004.

4. Murphy SL, Xu J, Kochanek KD, Curtin SC, Arias E. Deaths: final data for 2015. Natl Vital Stat Rep. 2017;66(6):1-75.

5. Kumar A, Cannon CP. Acute coronary syndromes: diagnosis and management, part I. Mayo Clin Proc. 2009;84(10):917938. doi:10.1016/s0025-6196(11)60509-0.

6. Hausenloy DJ, Yellon DM. Myocardial ischemia-reperfusion injury: a neglected therapeutic target. J Clin Invest. 2013;123(1):92-100. doi:10.1172/jci62874.

7. Al-Asadi JN, Kadhim FN. Day of admission and risk of myocardial infarction mortality in a cardiac care unit in Basrah, Iraq. Niger J Clin Pract. 2014;17(5):579-584. doi:10.4103/1119-3077.141422.

8. Salarifar M, Sadeghian S, Darabyan S, et al. Factors affecting inhospital mortality of acute myocardial infarction. Iran J Public Health. 2009;38(3):97-104.

9. Alhabib KF, Hersi A, Alfaleh $\mathrm{H}$, et al. Baseline characteristics, management practices, and in-hospital outcomes of patients with acute coronary syndromes: results of the Saudi project for assessment of coronary events (SPACE) registry. J Saudi Heart Assoc. 2011;23(4):233-239. doi:10.1016/j.jsha.2011.05.004.

10. Labarthe DR, Dunbar SB. Global cardiovascular health promotion and disease prevention: 2011 and beyond. Circulation. 2012;125(21):2667-2676. doi:10.1161/ circulationaha.111.087726.

11. Kessler T, Erdmann J, Schunkert H. Genetics of coronary artery disease and myocardial infarction--2013. Curr Cardiol Rep. 2013;15(6):368. doi:10.1007/s11886-013-0368-0.

12. Merry AH, Boer JM, Schouten LJ, et al. Smoking, alcohol consumption, physical activity, and family history and the risks of acute myocardial infarction and unstable angina pectoris: a prospective cohort study. BMC Cardiovasc Disord. 2011;11:13. doi:10.1186/1471-2261-11-13.

13. Avezum A, Makdisse M, Spencer F, et al. Impact of age on management and outcome of acute coronary syndrome: observations from the Global Registry of Acute Coronary Events (GRACE). Am Heart J. 2005;149(1):67-73. doi:10.1016/j. ahj.2004.06.003.

14. Newby LK, Bhapkar MV, White HD, et al. Predictors of 90day outcome in patients stabilized after acute coronary syndromes. Eur Heart J. 2003;24(2):172-181. doi:10.1016/ s0195-668x(02)00325-1.

15. Kochar A, Chen AY, Sharma PP, et al. Long-term mortality of older patients with acute myocardial infarction treated in US clinical practice. J Am Heart Assoc. 2018;7(13). doi:10.1161/ jaha.117.007230.

16. Canto JG, Goldberg RJ, Hand MM, et al. Symptom presentation of women with acute coronary syndromes: myth vs reality. Arch Intern Med. 2007;167(22):2405-2413. doi:10.1001/ archinte.167.22.2405.

17. Asgar Pour H, Norouzzadeh R, Heidari MR. Comparison of clinical presentation related on risk factors in older and younger patients with acute coronary syndrome. Int J Clin Cardiol. 2015;2:058. doi:10.23937/2378-2951/1410058.

18. Han JH, Lindsell CJ, Hornung RW, et al. The elder patient with suspected acute coronary syndromes in the emergency department. Acad Emerg Med. 2007;14(8):732-739. doi:10.1197/j.aem.2007.04.008.

19. Dali B. Clinical Profile, Dyslipidemia and ACS - a Correlation. JNMA J Nepal Med Assoc. 2014;52(195):907-913. doi:10.31729/jnma.2715.

20. Khatri P, Simkhada R. Study on conventional risk factors in acute coronary syndrome. J Univers Coll Med Sci. 2015;3(2):14. doi:10.3126/jucms.v3i2.14282.

21. Hwang SY, Park EH, Shin ES, Jeong MH. Comparison of factors associated with atypical symptoms in younger and older patients with acute coronary syndromes. J Korean Med Sci. 2009;24(5):789-794. doi:10.3346/jkms.2009.24.5.789.

22. Nobahar M, Vafaei A. Comparison of classic symptoms in acute coronary syndromes among young and old patients. The Journal of Qazvin University of Medical Sciences. 2005;9(34):18-22. [Persian].

23. Canto JG, Rogers WJ, Goldberg RJ, et al. Association of age and sex with myocardial infarction symptom presentation and inhospital mortality. JAMA. 2012;307(8):813-822. doi:10.1001/ jama.2012.199.

24. Ricci B, Cenko E, Vasiljevic Z, et al. Acute coronary syndrome: the risk to young women. J Am Heart Assoc. 2017;6(12). doi:10.1161/jaha.117.007519.

25. Geifman N, Rubin E. Towards an age-phenome knowledgebase. BMC Bioinformatics. 2011;12:229. doi:10.1186/1471 2105-12-229.

26. Milner KA, Funk M, Richards S, Vaccarino V, Krumholz HM. Symptom predictors of acute coronary syndromes in younger and older patients. Nurs Res. 2001;50(4):233-241. doi:10.1097/00006199-200107000-00007.

27. Naito R, Miyauchi K, Nojiri S, Suzuki N, Daida H. Differences in clinical features in patients with acute coronary syndrome and stroke: Japanese multicenter registry results. Intern Med. 2018;57(22):3233-3240. doi:10.2169/ internalmedicine.1020-18.

28. Duan JG, Chen XY, Wang $L$, et al. Sex differences in epidemiology and risk factors of acute coronary syndrome in Chinese patients with type 2 diabetes: a long-term prospective cohort study. PLoS One. 2015;10(4):e0122031. doi:10.1371/ journal.pone.0122031.

29. Khesroh AA, Al-Roumi F, Al-Zakwani I, Attur S, Rashed W, Zubaid M. Gender differences among patients with acute coronary syndrome in the Middle East. Heart Views. 2017;18(3):77-82. doi:10.4103/heartviews.heartviews_10_17.

30. Mirza AJ, Taha AY, Khdhir BR. Risk factors for acute coronary syndrome in patients below the age of 40 years. Egypt Heart J. 2018;70(4):233-235. doi:10.1016/j.ehj.2018.05.005.

31. Picariello $C$, Lazzeri $C$, Attanà $P$, Chiostri M, Gensini GF, Valente S. The impact of hypertension on patients with acute coronary syndromes. Int J Hypertens. 2011;2011:563657. doi:10.4061/2011/563657.

32. Al-Lamki L. Acute coronary syndrome, diabetes and hypertension: Oman must pay more attention to chronic non-communicable diseases. Sultan Qaboos Univ Med J. 2011;11(3):318-321.

33. Babu AS, Haneef M, Joseph AN, Noone MS. Risk factors among patients with acute coronary syndrome in rural kerala. Indian J Community Med. 2010;35(2):364-365. doi:10.4103/09700218.66863.

34. Goodacre S, Cross E, Arnold J, Angelini K, Capewell S, 
Nicholl J. The health care burden of acute chest pain. Heart. 2005;91(2):229-230. doi:10.1136/hrt.2003.027599.

35. El-Menyar A, Zubaid M, Sulaiman K, et al. Atypical presentation of acute coronary syndrome: a significant independent predictor of in-hospital mortality. J Cardiol. 2011;57(2):165171. doi:10.1016/j.jjcc.2010.11.008.

36. Lloyd-Jones D, Adams R, Carnethon M, et al. Heart disease and stroke statistics--2009 update: a report from the American Heart Association Statistics Committee and Stroke Statistics Subcommittee. Circulation. 2009;119(3):e21-181. doi:10.1161/circulationaha.108.191261.

37. Montalescot G, Dallongeville J, Van Belle E, et al. STEMI and NSTEMI: are they so different? 1 year outcomes in acute myocardial infarction as defined by the ESC/ACC definition (the OPERA registry). Eur Heart J. 2007;28(12):1409-1417. doi:10.1093/eurheartj/ehm031.

38. Reda AA, Mina MB, Taha Hussein AN. Pattern of risk factors and management strategies in patients with acute coronary syndrome. Menoufia Med J. 2018;31(2):378-386. doi:10.4103/ mmj.mmj_602_16. 